\title{
LARGE GROUP VERSUS SMALL GROUP- A TEACHING PRINCIPLE IN MEDICAL EDUCATION
}

\author{
Sudakshina Chakrabarti ${ }^{1}$
}

${ }_{1}^{1}$ Assistant Professor, Department of Anatomy, Saveetha Medical College, Chennai, Tamilnadu, India.

\section{ABSTRACT}

\section{BACKGROUND}

Medical education is an evolving scientific field with new modifications and changes in teaching style added continuously for the betterment of medical students. Small group teaching is a new trend compared to large group didactic lectures. Small group teaching is an active mode of teaching with participation from the students and thus results in better understanding of concepts. Large group teachings are conventional mode of teaching, which is preferred by teachers and students, as it exposes students to competition and newer concepts.

Aim- To compare and analyse the teaching methodologies in small and large group and its benefits and disadvantages on the students.

\section{MATERIALS AND METHODS}

This descriptive study conducted in Saveetha Medical College, Chennai, India on 1st MBBS students for teaching Anatomy over a period of academic year. In this study, Anatomy was taught in large and small groups over an equal timeframe for more or less equal portions. A feedback analysis was done for a questionnaire given to the students, which clearly showed students preferred small group teaching. A performance analysis was also conducted after large and small group teachings and the performancemeans were analysed by paired t-test, which too showed a significant difference in the mean scores attained by students on internal assessment exams.

\section{RESULTS}

Questionnaire analysis showed students preferred small group teaching compared to large group teaching. The analysis of the internal assessment performances after small group teaching showed a significant improvement compared to that after large group teaching.

\section{CONCLUSION}

Thus, this study attempts not only at subjective testing of the modification of teaching but also includes objective testing by testing the performance of students both after large group and small group teachings.

\section{KEY WORDS}

Medical Education, Questionnaire, Internal Assessment.

HOW TO CITE THIS ARTICLE: Chakrabarti S. Large group versus small group- a teaching principle in medical education. J. Evolution Med. Dent. Sci. 2018;7(34):3786-3790, DOI: 10.14260/jemds/2018/849

\section{BACKGROUND}

Teaching plays a huge role in laying down the foundation in developing future doctors who can appropriately serve the society. Teachings in medical colleges in India are preferentially done in large groups as didactic lectures for the theoretical portions and smaller groups are preferred for practical demonstrations. The role of obtaining feedback at regular intervals, though not a regular practice and not yet incorporated in the system, some young medicals have started its practice and it seems to be very effective. With advances in medical education the medical college teachers are evolving different methods of teaching which includes tutorials, seminars by having a panel of experts, brainstorming sessions videotapes, class discussions, small group discussions, case studies, role playing etc.(1)

'Financial or Other Competing Interest': None.

Submission 06-07-2018, Peer Review 03-08-2018,

Acceptance 09-08-2018, Published 20-08-2018.

Corresponding Author:

Dr. Sudakshina Chakrabarti,

Assistant Professor,

Department of Anatomy,

Saveetha Medical College,

Chennai, Tamilnadu, India.

E-mail: sudhianat@gmail.com

DOI: 10.14260/jemds/2018/849
During the late 1990s, the medical council of India made it mandatory for all medical schools to have medical education cells for faculty development and providing teaching learning resources. Large group teaching in the form of didactic lectures are the oldest forms of teaching, which are still extensively used in medical colleges in India. Didactic lectures are age old proven effective method of transferring knowledge and basic concepts to large groups and can be used to stimulate thought process in the younger generations of doctors. Didactic lectures are tuned to encourage passive learning among students and they are provided with loads of information at a short span of time, but there are limitations regarding critical thinking and appraisal of the knowledge imparted to them.

Anatomy as a subject in first MBBS has extensive portions and many subdivisions, which needs the student to know in detail about Gross Anatomy, Histology, Osteology, Embryology, and to certain extent Surface Anatomy and Radiological Anatomy also. Among these in our University, Gross Anatomy and Histology deserves special mention.(2) In this hour, there is a need to incorporate interactive and effective teaching practices into the medical curriculum for the upcoming future doctor to meet the challenges faced by them during their practice. Most of the 1st MBBS on obtaining oral feedback feel didactic lectures in Anatomy are boring and they feel it is very difficult to concentrate and understand 
the topics taught.(3) A large or a small group lecture can be made interactive by implementing one or more flexible methods and including them during teaching. These include Silent reflection, Buzz groups, Rounds, Brain storm sessions, Fish Bowls, Crossovers etc. A lecturer used to take 400 students lecture in a large group would define 50 as a small group, whereas in Saveetha Medical College where the intake is 150 medical students per year a group of 10 - 15 students can be considered as a small group. Small group teaching is beneficial in transferring analytical, communication and presentation skills. Students tend to enjoy small group sessions more and they are no doubt beneficial for them. Small group teaching is more beneficial if certain guidelines are followed, which includes pre-reading of the topic to be dealt, punctuality to be maintained, all criticism should be constructive and the facilitator should try and enhance participation of each and every member of the group and providing handouts to the students for better idea of the topic discussed.(4) The medical education curriculum is conducted in two separate contexts, i.e. classroom or laboratory context and clinical contexts which requires exposure to hospital and community. The basic science teaching is undergoing a rapid change in recent times by providing a deeper understanding in molecular biology, genetics etc. In India, the curriculum is still divided into pre-clinical and clinical phases and each one of the components are dealt separately by biomedical scientists and by clinicians respectively. In countries like UK, Canada, Australasia curricula are more integrated and system based, which has changed the relation of basic science departments and clinicians.(5) In India, there is a need at present to teach clinically significant medical anatomy which can be dealt easily in small group. In this present study there is an attempt to teach Anatomy to first year MBBS students in small group and also in large group and compare the subjective feedback with the internal assessment performances of the students. The important small group methods popular in medical schools are tutorials, seminar, problem based learning, bedside and ward based clinical teaching.(6) The design of small group teaching sessions should be based on the major principles including the introduction of the topic, ground rules, group maintenance role and the task role, activity, briefing and debriefing.(7) While establishing a small group, it should be kept in mind that the small group environment must be designed to promote cooperation, rather than competition, to facilitate trust for working together to learn. In order to achieve a better small group teaching and learning environment, it is important to develop appropriate groups so that students can be actively involved in the activities.(8)

\section{Aims and Objectives}

- The Batch of 2015 - 16, 1 15t MBBS students were subjected to large and small group teaching of the equal subdivisions of the entire Anatomy syllabus.

- Develop a standard questionnaire- to acquire the feedback of students on their opinion for small group and large group teaching in Medical Anatomy.

- Analyse the feedback of students on small group and large group teaching methodologies.

- Observe the internal assessment performance of the students after exposing them to each of the above group and comparing the performance.

\section{MATERIALS AND METHODS}

The descriptive study design was explained to the $1^{\text {st }}$ MBBS students and consent was obtained from the students to conduct the study on 2015 - 16 batch. Students were taken into confidence that their identities will not be exposed at any time during the study period. Students not willing to participate were excluded from the study. Institution ethical clearance was obtained prior to the commencement of the study.

150 medical students belonging to $1^{\text {st }}$ MBBS 2015 - 16 batch were exposed to- i) Large group traditional method of teaching for a period of first 4 and a half months and then they were exposed to- ii) Small group discussion based active teaching and learning for a period of next 4 and a half months. The portion of the curriculum was approximately divided into 2 equal halves for the above 2 periods. Thus, the portion completed in gross anatomy in the first four and a half months were 1) Upper limb, 2) Lower limb, 3) Abdomen and Pelvis along with related Osteology, Histology, Embryology and Surface Anatomy. The portions completed in small group teaching which was followed in next four and a half months were- 1) Head and neck, 2) Thorax, 3) Neuroanatomy along with relevant osteology, embryology histology and surface anatomy.

The large group teaching was in the form of didactic lectures in a traditional way and did not involve any interaction, whereas the small group teaching was conducted in groups of 12 students in each groups and faculty were asked to facilitate the sessions. In small group method of teaching handouts were provided to the students prior to the sessions and students were asked to read and come as topics were given to them one week prior to teaching. There are three main activities that small group teachers have to manage simultaneously: Managing the group, managing activities in groups and managing the learning. The role of the teacher is typically that of facilitator of learning: leading discussions, asking open-ended questions, guiding process and task and enabling active participation of learners and engagement with ideas. 1. Start and finish group workkeeping to time, ensuring outcomes and tasks are explained and that the activities draw to a close with learning needs being achieved, 2. Maintain the flow of content- ensuring learning follows in a logical sequence and providing stimulus materials and questions, 3. Manage group dynamics, 4. Facilitate goal achievement- of the wider curriculum, of the session and those identified by the learners themselves, 5 . Manage group environment- both physical and psychological.(9) The next step was to prepare a validated questionnaire for a satisfactory psychometric analysis. The questionnaire forms the backbone of this study. The domains of the questions were first assessed according to the requirements of the study and then items, or questions were framed and validation was carried out in steps. The fourpoint Likert scale was used to evaluate the response.

\section{Validation of Questionnaire}

1. Content validity- the framed questions were discussed with 5 experts from the same specialty and content validity index was near $100 \%$.

2. Face validity- by non-experts.

3. Construct validity was tested using statistical analysis of questions answered and the Cronbach's Alpha was 0.72, which indicated the questionnaire was reliable. 
4. Questionnaire has been provided in Fig. 1.

\section{Performance Analysis of Students}

The 2 test results were analysed, which was an overall average of theory and practical which were conducted at the end of large group and small group teachings. Utmost confidentiality of the performance of students were maintained throughout the study in a password protected computer. Thus, this study attempted to capture the subjective assessment of student's feedback and an objective assessment of their performance in internal assessments in respect to large and smaller group teaching. Statistical analysis including descriptive statistics such as frequency, percentage and mean \pm standard deviation was used in this study for the analysis of the performance of the students. Furthermore, analysis of frequencies (chi-square test) was used to compare the qualitative variables. This was used for non-parametric questionnaire analysis and SPSS 17 were used for statistical analysis with a p-value less than 0.05 considered significant.

All data used in this study was anonymised using unique identification codes and stored in secure location. This was carried out after clearance of Institutional Scientific Review Board.

\section{RESULTS}

A four-item point Likert scale was used to evaluate the response. The points of strongly agree and agree were grouped as positive response and the points of disagree and strongly disagree were grouped as negative response. The neutral response was avoided in the questionnaire to make the students respond appropriately and avoid non-response bias. As shown in Fig. 2 based on the questionnaire analysis, it was observed that students participated in small group teaching and their understanding was better in small group discussion-based teaching. About $78 \%$ of students easily approached the teachers in small group teaching. About 68\% of low achievers and $82 \%$ of high achievers felt they benefited from small group teaching. About $75 \%$ of students felt they were motivated to learn more in small group teaching. Question bank discussion was more effective in small group as participation of students were more. About $79 \%$ of students had more concentration in small group based discussion rather in large group didactic lectures. Students felt discussion of newer concepts and applied aspect was better in large group didactic lectures, as small group discussion was more focused on specific key points and must know aspects of the curriculum. As Likert scale is not dependent on clear-cut parameters, a non-parametric statistical analysis in form of expressing in percentage was done.

As shown in Fig. 3 the second part of the study was to analyse the marks obtained after Test 1 which was conducted at the end of four and a half months of large group teaching compared to the performance of students after Test 2 which was conducted at the end of four and a half months of small group discussion-based teaching. On comparing the performance, it was seen that the percentage of students who obtained $51-60 \%$ of marks was significantly high ( $p>0.05)$ after small group teaching and it was $68 \%$ compared to $45 \%$ after large group teaching. Percentage of students scoring less than $30 \%$ marks were also reduced after small group teaching from $29 \%$ to $19 \%$. Percentage of students scoring $61 \%$ and above also showed an increase after small group teaching from $23 \%$ to $31 \%$. Thus, it was invariably clear that the small group discussion-based teaching is extremely beneficial for students.

The overall mean value of both test scores were subjected to paired T-test and T score was 3.45 to find out whether the null hypothesis can be rejected, and it was seen the $t$ statistics was $>$ df 149 at p-value of 0.05 , thus it showed that there was significant difference in mean score between internal assessment 1 and internal assessment 2 , thus we can accept the alternate hypothesis.

\begin{tabular}{|c|c|c|c|c|c|c|c|c|c|}
\hline $\begin{array}{l}\text { SERIAL } \\
\text { NO }\end{array}$ & $\begin{array}{l}\text { Students are asked to listen to instructions } \\
\text { carefully before ticking their appropriate } \\
\text { decision in LG OR SG BOXES. } \\
\end{array}$ & \begin{tabular}{|l|} 
LG \\
SA
\end{tabular} & \begin{tabular}{|l|l|l|l|l} 
L & \\
$A$
\end{tabular} & $\begin{array}{l}G \\
D A\end{array}$ & SDA & & SG & & $\begin{array}{ll}S G A \\
S G\end{array}$ \\
\hline & QUESTIONNARE & & & & & & & & \\
\hline 1 & I Understood and followed the classes & & & & & & & & \\
\hline 2 & $\begin{array}{l}\text { I participated in the class by answering, } \\
\text { involving in group discussion, presenting, } \\
\text { etc. }\end{array}$ & & & & & & & & \\
\hline 3 & $\begin{array}{l}\text { I had motivation to learn the subject after } \\
\text { the classes }\end{array}$ & & & & & & & & \\
\hline 4 & $\begin{array}{l}\text { If felt there was more discussion of newer } \\
\text { concepts and applied aspect }\end{array}$ & & & & & & & & \\
\hline 5 & $\begin{array}{l}\text { Ifelt the classes were beneficial for low } \\
\text { acheivers }\end{array}$ & & & & & & & & \\
\hline 6 & $\begin{array}{l}\text { If felt the classes were beneficial for high } \\
\text { acheivers }\end{array}$ & & & & & & & & \\
\hline 7 & I had concentration in classes & & & & & & & & \\
\hline 8 & $\begin{array}{l}\text { I could approach teachers with my } \\
\text { difficulties }\end{array}$ & & & & & & & & \\
\hline 9 & $\begin{array}{l}\text { I felt Question bank discussion was more } \\
\text { effective }\end{array}$ & & & & & & & & \\
\hline 10 & $\begin{array}{l}\text { Overall satisfaction for smaller group or } \\
\text { large group classes }\end{array}$ & & & & & & & & \\
\hline \multicolumn{10}{|c|}{$\begin{array}{l}\text { LG-Large group classes, SG-Smaller group classes, SA-Strongly agree, A-Agree, DA- Disagree, SDA- } \\
\text { Strongly Disagree }\end{array}$} \\
\hline
\end{tabular}

Figure 1 


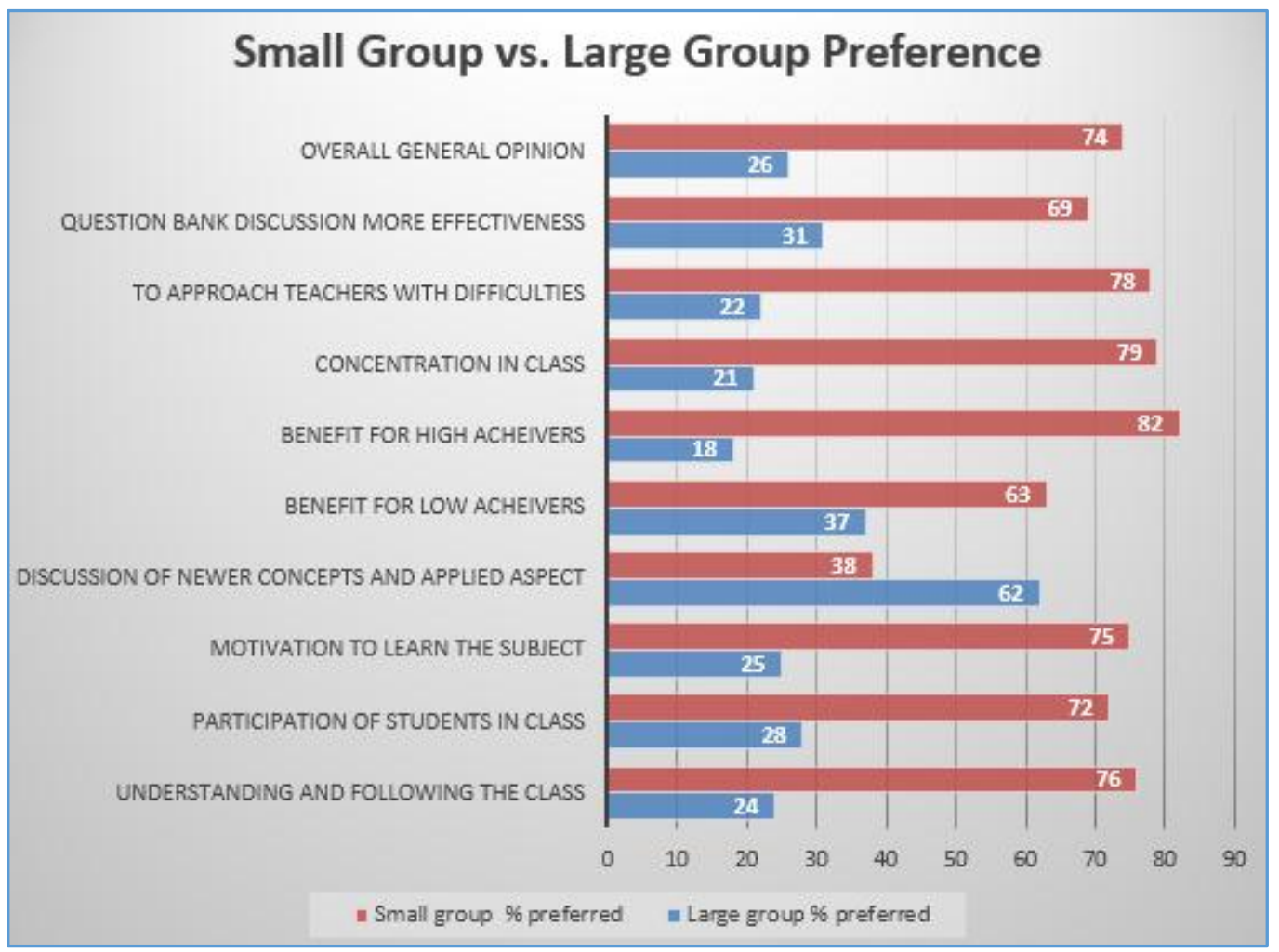

Figure 2

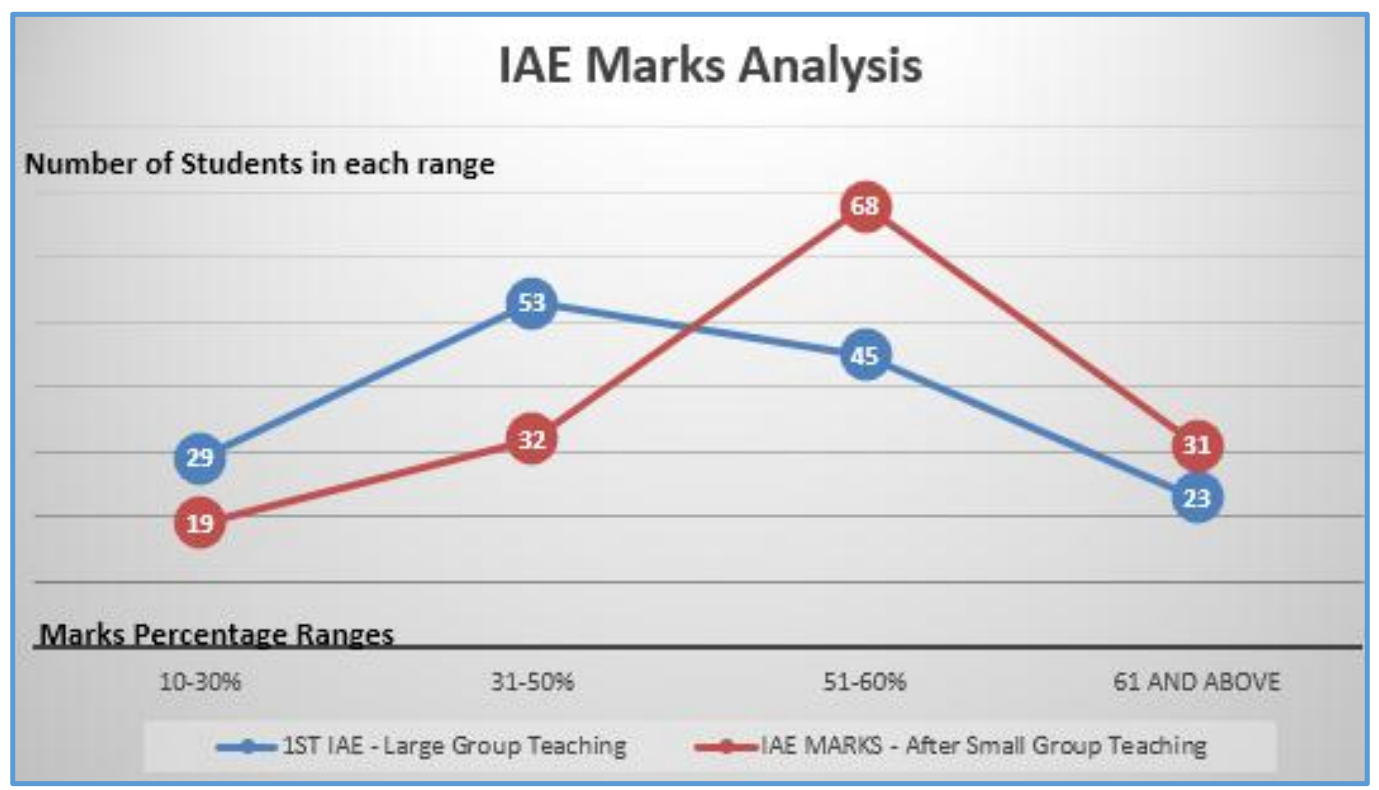

Figure 3

\section{DISCUSSION}

In the study conducted by Steinert $\mathrm{Y}$ in which the aim was to assess student perceptions for effective small group teaching during preclinical training in a medical school that promotes an integrated, systems-based undergraduate curriculum. Students in small groups could relate easily with a nonthreatening group atmosphere, they could integrate basic science knowledge to clinical aspects and pedagogical skills that encouraged self-thinking and problem-solving approach Small group teaching encouraged questions raised by inquisitive minds of students, to work as a team and to learn to solve problems independently according to this study.(10) In the present study, the students felt the small group classes were highly interactive and they were motivated to learn the subject. In the study by Reenu Kumari et al for-teaching methodology for theory classes $51 \%$ of students wanted to study in small groups along with usage of interactive media, while $22 \%$ selected problem based learning approach. Only $18 \%$ were in favour of traditional lecture-based classes and $9 \%$ for interactive media. Students often find it difficult to recollect theory classes while performing dissection. This study also throws light on the importance of receiving feedback from students at intervals, as it helps to identify areas of strength and/or weakness of teaching modalities used so that steps can be taken to reform teaching.(11) In the present study, the feedback questionnaire was prepared over 
a period of six months after taking into consideration of all possible factors which can lead to bias. In the study by Jaishwal 2015 the best method for theory classes was teaching in small groups with interactive media $(45.73 \%)$ followed by lecture (24.03\%).(12) Another study reported that students preferred to work in teams. In fact when compared to traditional lectures, small-group discussion methods have been found to promote communication, problem-solving and interpersonal skills.(13) Of the participating students, 68 (51.3\% females and $48.7 \%$ males) were taught in the lecture group (Control group), while 66 (46.8\% females and 53.2\% males) participated in the small-group discussions (Experimental group). 7). No statistical differences were found in the acquisition of knowledge $(p=0.25)$ between the control group (Mean score $=4.30 \pm 1.2$ ) and experimental group (Mean score $=4.49 \pm 1.11$ ). The students in the experimental group scored significantly higher (mean score= $7.29 \pm 1.03$ ) than those in the lecture group (mean score $=$ $6.24 \pm 1.30)$ when skill performance was tested $(\mathrm{p}=8.9 \times$ $10^{-7}$ ). This study compared quantitative information on both cognitive and psychomotor outcomes for a cohort of firstyear dental students randomly divided into small-group discussion and lecture format sessions. The goal of this study was not to collect students' view, but students in the experimental group enjoyed their active participation and thanked the facilitators for the change in the delivery format. Positive feedback was also received from the three facilitators. (14) In the present study feedback is the backbone and to add upon the views of students, the scores of the 2 term exams have been compared and it showed a significant rise in the number of students, i.e. $23 \%$ of increase in number of students scoring marks in the range of (51 to 60) \% from large group to small group teaching. Thus, as in our university the pass percentage is $50 \%$, so the number of students passed at the end of small group teaching was significantly higher than at the end of large group teaching. In the study conducted on residents of Orthopaedic department in Iran two groups of Orthopaedic training courses residents were studied. Two methods of training were compared, i.e. one group was exposed to small group discussion-based training and another group was exposed to traditional large group training. The State board exams were compared at end of 4 years of residency program, which showed that the students trained in small groups were significantly more successful in both written and OSCE tests.(15) This performance based comparison is also done in the present study, which shows the objective benefit in success rates and marks obtained by the students in the examination after exposing them to 2 different modalities of teaching.

\section{CONCLUSION}

Small group teaching has multiple benefits, some of them are positive interactions among students from diverse cultural backgrounds, exchange of information, academic achievement, possession of new knowledge and fine skills, aptitude to work out clinical problems, motivation to learn, confidence and social development. As the teacher's role in small group teaching is more of a facilitator rather than a traditional teacher, small group teaching can be carried out effectively with limited resources and personnel. The test results also showed a significant improvement of students after small group teaching. Thus, it can be concluded that small group teaching was appreciated and preferred by the medical students.

\section{ACKNOWLEDGMENT}

Mr. VenkatKumar N. CEO, Karya Technologies for Graphics support.

\section{REFERENCES}

[1] Rathnakar UP, Ullal SD, Pai PG, et al. Is small group teaching among the under graduate dental students really effective? Journal of Clinical and Diagnostic Research 2011;5(4):822-5.

[2] Sudakshina C, Vijayalakshmi, Gunapriya R. Problems and difficulties encountered by first MBBS students in learning Medical Anatomy and some of its solutions - a feedback study. Int J Pharma Bio 2017;8(4):B40-8.

[3] Chakrabrati S, Shilpakala LB, Raghunath G, et al. Teaching and learning perception of anatomy by first MBBS 2014-15 batch students. Indian J Clinical Anatomy and Physiology 2017;4(1):87-91.

[4] Surgenor P. Teaching toolkit. Effect of Assessment on Learning. University College Dublin January 2010. https://www.ucd.ie/t4cms/UCDTLT0031.pdf

[5] McKimm J. Current trends in undergraduate medical education: program and curriculum design. Samoa Medical Journal 2010;2(2):40-48.

[6] Jones RW. Learning and teaching in small groups: characteristics, benefits, problems and approaches. Anaesth Intensive Care 2007;35(4):587-59.

[7] Crosby J. Small group teaching: centre for medical education. Scotland: University of Dundee 2005: p. 3.

[8] Gaudet AD, Ramer LM, Nakonechny J, et al. Smallgroup learning in an upper-level university biology class enhances academic performance and student attitudes toward group work. PLoS One 2010;5(12):e15821.

[9] Mckimm J, Morris C. Small group teaching. Br J Hosp Med (Lond) 2009;70(11):654-7.

[10] Steinert Y. Student perceptions of effective small group teaching. Med Educ 2004;38(3):286-93.

[11] Kumari R, Yadav AK, Singh B, et al. Evaluating anatomy teaching methodology as per the percipience of first year M.B.B.S. students - a questionnaire based study. International Journal of Basic and Applied Medical Sciences 2015;5(2):240-7.

[12] Jaiswal R, Sathe S, Gajbhiye V, et al. Students perception on methods of anatomy teaching and assessment. Int J Anat Res 2015;3(2):1103-8.

[13] Ferreri SP, O'Connor SK. Redesign of a large lecture course into a small-group learning course. Am J Pharm Educ 2013;77(1):13.

[14] Arias A, Scott R, Peters OA, et al. Educational outcomes of small-group discussion versus traditional lecture format in dental students' learning and skills acquisition. J Dent Educ 2016;80(4):459-65.

[15] Tabrizi A, Pourfeizi HH, Aslani H, et al. Effect of small group discussion in residency education versus conventional education. Res Dev Med Educ 2016;5(1):47-9. 